\title{
Deep vein thrombosis during long-term surveillance of patients with liver transplantation
}

\author{
Alice Balaceanu ${ }^{1}$ (D) \\ Received: 9 December 2018 / Accepted: 27 February 2019 / Published online: 8 March 2019 \\ (C) The Author(s) 2019
}

\begin{abstract}
Background In the European Liver Transplant Registry, there are 137,863 liver transplantations recorded. Forty-one percent of patients survived 20 years after liver transplantation in the European countries. From 1988, when the US database for liver transplantation was created, to 2006, there are more than 56,000 liver transplants. Almost 80\% of the liver transplant recipients survived 5 years after transplantation. The incidence of deep vein thrombosis (DVT) in the European population is 70-140/ 100.000 person-years. Cancer, paresis, immobilization, thrombophilia, inflammatory bowel disease, replacement hormonal or contraceptive therapies are associated with an increased risk of occurrence DVT or complications. The incidence of DVT in longterm surveillance of liver transplant recipients is unknown. Immunosuppressive therapy, thrombophilia abnormalities, hepatitis $\mathrm{C}$ and hepatocellular carcinoma recurrence, renal insufficiency, malignant tumours, obesity and diabetes were associated with DVT in long-term post-liver transplantation. The reported maximum time between liver transplantation and DVT was 210 days.

Aim The aim of the study is to update existing data in the literature regarding the occurrence and management of deep vein thrombosis in liver transplant patients over the long-term surveillence period.

Conclusions There are no specific guideline recommendations regarding acute DVT treatment in long-term surveillance after liver transplantation. Low molecular weight heparin (LMWH), unfractionated heparin (UFH) and vitamin K antagonist (VKA) are the anticoagulants used in specific complications post-transplantation. The safety and the efficacy of direct anticoagulants in liver transplantation recipients need to be assessed in future trials. Given that long-term survival of liver transplantation is much improved, complications associated with transplantation and ageing require appropriate cardiovascular guidelines.
\end{abstract}

Keywords Deep vein thrombosis $\cdot$ Liver transplantation $\cdot$ Post-transplant long-term

\section{Introduction}

The incidence of deep vein thrombosis (DVT) in the European population is 70-140/100.000 person-years [1]. Cancer, paresis, immobilization, thrombophilia, inflammatory bowel disease, replacement hormonal or contraceptive therapies are associated with an increased risk of occurrence DVT or complications [1,2].

From 1988, when the US database for liver transplantation was created, to 2006, there are more than 56,000 liver transplants [3]. Almost $80 \%$ of the liver transplant recipients

Alice Balaceanu

alicebalaceanu@yahoo.com

1 Internal Medicine Department, "Sf. Ioan” Clinical Emergency Hospital, "Carol Davila" University of Medicine and Pharmacy, Sos. Vitan-Bârzeşti nr. 13, Bucharest, Romania survived 5 years after transplantation [3, 4]. In the European Liver Transplant Registry, there are 137,863 liver transplantations recorded [4]. Forty-one percent of patients survived 20 years after liver transplantation in the European countries [5].

\section{Aims}

The long-term survival of patients with liver transplantation increases the probability of deep vein thrombosis associated with physiological ageing, metabolic syndrome, side effects of immunosuppressive therapy, hepatitis $\mathrm{B}$ or $\mathrm{C}$ recurrence, or simply age-related comorbidities, involving immobilization. The aim of the study is to update the existing data in the literature regarding the occurrence and management of deep venous thrombosis in liver transplant patients over the longterm surveillance period. 


\section{Methods}

To find available data on deep vein thrombosis in long-term surveillance of liver transplantation recipients, a search in Web of Science Core Collection, PubMed, Elsevier ScienceDirect, Cochrane, Google Scholar was performed with the terms liver transplantation, long-term post-liver transplantation, deep vein thrombosis post-liver transplantation and thromboembolism post-liver transplantation. The search was limited to English full-text articles and reviews in humans, with case reports. Sixty-four articles were found between 1995 and 2018, with 21 articles meeting the criteria.

\section{Results and discussion}

The incidence of DVT in long-term surveillance of liver transplant recipients is unknown. Ishitani and colleagues reported an incidence of $3.7 \%$ of symptomatic venous thromboembolic disease and $2.7 \%$ of DVT [6]. The maximum time between liver transplantation and DVT in their study was 210 days [6]. Annamalai and colleagues reported an incidence of DVT of $8.6 \%$ [7]. In their trial, the maximum time between liver transplantation and DVT was 80 days [7].

Patients with liver transplantation have a hypercoagulable status that can lead to thrombotic complications both in the short and long term [8]. Peripheral vascular thrombosis increases the morbidity and the mortality in the long-term surveillance of these patients, and the haemostatic abnormalities could be complex [8]. The immunosuppressive treatment, malignant tumours, recurrence of hepatocellular carcinoma or hepatitis B or C, thrombophilia abnormalities, renal insufficiency, obesity, diabetes and also ageing increase the risk of developing deep vein thrombosis in patients who survive for long periods of time.

\section{Immunosuppresive treatment: Immunosuppressive therapy is essential in the post-transplant long-term surveillance}

After 6 months of double or triple immunosuppressive therapy, monotherapy is given if the haepatic function is appropriate and there is no rejection [9]. Long-term monotherapy involves commonly a calcineurin inhibitor (tacrolimus or cyclosporine) [9-11]. The most common long-term complications of immunosuppressive therapy in patients with liver transplantation are hypertension, metabolic disease (diabetes mellitus, hyperlipidaemia, obesity), infections, renal insufficiency, malignancy, bone disease and recurrence of liver disease [9]. Hypertension and dyslipidaemia are not associated with a high risk of venous thrombosis, but obesity does [12, 13]. The authors of a study reported that in a period of up to 3 years of post-transplant surveillance, $31 \%$ of patients became obese [14]. The creatinine clearance, microalbuminuria, urinary albumin-to-creatinine ratio and chronic kidney disease are also associated with venous thromboembolism [12,13]. Chronic kidney disease was reported in up to $90 \%$ of liver transplantation patients, mainly due to preexisting disease, nephrotoxic immunosuppressive medication and long-term cardiovascular complications [11]. The endstage renal disease, previous venous thromboembolism and diabetes are also reported as predictive factors for venous thromboembolism [13, 15]. In 2016, 28.8\% of liver transplant recipients in the USA were reported with diabetes [6].

Generally, oral corticosteroids are recommended for about 3-6 months after transplantation, although some transplant centers recommend low-dose treatment for an indefinite period [16]. Administration of corticosteroids increases 1.2 to 2 times the risk of deep vein thrombosis [12]. The risk increases with the cumulative dose of corticosteroids and is independent of the underlying disease [12].

\section{Recurrence of haepatic disease: Hepatitis C and hepatocellular carcinoma have a high recurrence rate after liver transplantation [12]}

Multiple authors reported that the probability for recurrence of HCV infection is between 60 and $90 \%$ and between 12.9 and $38.7 \%$ for recurrence of hepatocellular carcinoma on the liver transplant [11, 17-19]. Martinelli and colleagues reported an incidence rate of venous thrombosis of 1.06 per 100 patientyears in liver transplantation recipients for hepatocellular carcinoma, followed for an average of 7.17 years [20]. The mechanisms of venous thrombosis could be both persistence of fibrin deposition after hepatic transplantation for hepatocellular carcinoma and thrombophilia abnormalities (factor V Leiden and prothrombin G20210A mutation) of the recipients [20].

\section{Malignant tumours: The incidence of malignant tumours post-liver transplantation ranges between 2.3 and $12.9 \%$ and the risk is fivefold higher than in the general population [3].}

The risk of venous thromboembolism increases in cancer by four to seven times [1].

Other risk factors: All these factors are associated with an increased risk of DVT in post-transplant long-term surveillance. Acquired or congenital thrombophilia, antiphospholipid syndrome and elevated serum homocysteine are important prothrombotic factors in Caprini risk score, but prophylactic treatment for any patient is still debated, due to the low risk of thrombosis $[2,17]$.

There are no specific guideline recommendations regarding acute DVT treatment in long-term surveillance after liver transplantation. The special situations exposed by the guidelines for the management of DVT, cancer, chronic kidney 
disease and obesity need attention [1, 2]. In cancer, low molecular weight heparin (LMWH) is safer as unfractionated heparin (UFH) for initial or long-term treatment of DVT [1, 2]. LMWH or vitamin $\mathrm{K}$ antagonist (VKA) is recommended for long-term treatment ( 3 to 6 months) in patients with cancer [1]. After 6 months, the anticoagulation treatment is individualized [1]. In chronic kidney disease, creatinine clearance less than $30 \mathrm{~mL} / \mathrm{min}$ is preferred UFH [1], even subcutaneous [2]. The direct oral anticoagulants for DVT/thromboembolism are used in specific conditions [1, 2, 21], but their safety and efficacy in liver transplantation recipients need to be assessed in future trials.

\section{Conclusion}

Given that long-term survival after liver transplantation is much improved, complications associated with transplantation and ageing require appropriate cardiovascular guidelines, particularly in the management of deep vein thrombosis and venous thromboembolism.

Funding No funding.

\section{Compliance with ethical standards}

Conflict of interests The author declares that there are no conflict of interests.

Open Access This article is distributed under the terms of the Creative Commons Attribution 4.0 International License (http:// creativecommons.org/licenses/by/4.0/), which permits unrestricted use, distribution, and reproduction in any medium, provided you give appropriate credit to the original author(s) and the source, provide a link to the Creative Commons license, and indicate if changes were made.

Publisher's note Springer Nature remains neutral with regard to jurisdictional claims in published maps and institutional affiliations.

\section{References}

1. Mazzolai L, Aboyans V, Ageno W, Agnelli G, Alatri A, Bauersachs R, Brekelmans MPA, Büller HR, Elias A, Farge D, Konstantinides S, Palareti G, Prandoni P, Righini M, Torbicki A, Vlachopoulos C, Brodmann M (2017) Diagnosis and management of acute deep vein thrombosis: a joint consensus document from the European society of cardiology working groups of aorta and peripheral vascular diseases and pulmonary circulation and right ventricular function. Eur Heart J 00:1-14. https://doi.org/10.1093/eurheartj/ehx003

2. Spandorfer J, Galanis T (2015) Deep vein thrombosis. Ann Intern Med 162(9):ITC1. https://doi.org/10.7326/AITC201505050

3. Levitsky J, Cohen SM (2006) The liver transplant recipient: what you need to know for long-term care. J Fam Pract 55(2):136-144

4. Kim WR, Lake JR, Smith JM, Schladt DP, Skeans MA, Harper AM, Wainright JL, Snyder JJ, Israni AK, Kasiske BL (2018)
OPTN/SRTR 2016 Annual Data Report: Liver. Am J Transplant 18(Supp11):172-253. https://doi.org/10.1111/ajt.14559

5. European Liver Transplant Registry. www.eltr.org. Accessed 04 Sept 2018

6. Ishitani M, Angle J, Bickston S, Caldwell S, Isaacs R, Pruett T (1997) Liver transplantation: incidence and thrombosis and pulmonary emboli. Transplant Proc 29(7):2861-2863

7. Annamalai A, Kim I, Sundaram V, Klein A (2014) Incidence and risk factors of deep vein thrombosis after liver transplantation. Transplant Proc 46(10):3564-3569. https://doi.org/10.1016/j. transproceed.2014.09.113

8. Arshad F, Lisman T, Porte RJ (2013) Hypercoagulability as a contributor to thrombotic complications in the liver transplant recipient. Liver Int 33(6):820-827. https://doi.org/10.1111/liv.12140

9. Gaglio PJ, Cotler SJ. Liver transplantation in adults; long-term management of transplant recipients. www.uptodate.com. Accessed 05 Sept 2018

10. Sussman NL, Vierling JM. Liver transplantation in adults: overview of immunosuppression. www.uptodate.com. Accessed 05 Sept 2018

11. Bhat M, Al-Busafi SA, Deschenes M et al (2014) Care of the liver transplant patient. Can J Gastroenterol Hepatol 28(4):213-219

12. Bauer KA, Lip GYH. Overview of the causes of venous thrombosis. www.uptodate.com. Accessed 05 Sept 2018

13. Clinical Practice Guidelines EASL (2016) Liver transplantation. J Hepatol 64(2):433-485. https://doi.org/10.1016/j.jhep.2015.10.006

14. Richards J, Gunson B, Johnson J, Neuberger J (2005) Weight gain and obesity after liver transplantation. Transpl Int 2005;18(4):461466

15. Salami A, Qureshi W, Kuriakose P, Moonka D, Yoshida A, Abouljoud M (2013) Frequency and predictors of venous thromboembolism in orthotopic liver transplant recipients: a single-center retrospective review. Transplant Proc 45(1):315-319. https://doi. org/10.1016/j.transproceed.2012.06.060

16. Issa DH, Alkhouri N (2015) Long-term management of liver transplant recipients: a review for the internist. Cleve Clin J Med 82(6): 361-372. https://doi.org/10.3949/ccjm.82a.14072

17. Roberts MS, Angus DC, Bryce CL, Valenta Z, Weissfeld L (2004) Survival after liver transplantation in the United States: a disease specific analysis of the UNOS database. Liver Transpl 10(7):886897

18. Halazun KJ, Najjar M, Abdelmessih RM, Samstein B, Griesemer AD, Guarrera JV, Kato T, Verna EC, Emond JC, Brown RS Jr (2017) Recurrence after liver transplantation for hepatocellular carcinoma: a new MORAL to the story. Ann Surg 265(3):557-564. https://doi.org/10.1097/SLA.0000000000001966

19. Marrero JA, Kulik LM, Sirlin CB, Zhu AX, Finn RS, Abecassis MM, Roberts LR, Heimbach JK (2018) Diagnosis, staging, and management of hepatocellular carcinoma: 2018 practice guidance by the American Association for the Study of Liver Diseases. Hepatology. 68(2):723-750. https://doi.org/10.1002/hep.29913

20. Martinelli I, Ponziani FR, Maino A, Bhoori S, Abbattista M, Maggi U, de Feo TM, Bucciarelli P, Artoni A, Longhi E, Serafini M, Rossi G, Mazzaferro V (2017) Thrombosis after liver transplantation for hepatocellular carcinoma. PLoS One 12(10):e0186699. https://doi. org/10.1371/journal.pone.0186699. eCollection 2017

21. Becattini C, Agnelli G (2016) Treatment of venous thromboembolism with new anticoagulant agents. J Am Coll Cardiol 67(16): 1941-1955. https://doi.org/10.1016/j.jacc.2016.01.072 